\title{
Ecological-economic modelling for the sustainable management of biodiversity
}

\author{
L. Doyen ${ }^{1,5,{ }^{*}, \text { A. Cissé }}{ }^{7}$, S. Gourguet ${ }^{1,3}$, L. Mouysset ${ }^{6}$, P.-Y. Hardy ${ }^{1}$, C. Béné ${ }^{4}$, F. Blanchard ${ }^{7}$, \\ F. Jiguet ${ }^{1}$, J.-C. Pereau ${ }^{5}$, O. Thébaud ${ }^{2,3}$
}

1 CNRS-MNHN, 55 rue Buffon, 7005 , Paris, France

5 GREThA, University Montesquieu Bordeaux IV, Avenue Léon Duguit, Pessac, France

7 IFREMER, Laboratoire Ressources Halieutiques de Guyane, Guyane, France

3 CSIRO Marine and Atmospheric Research, 41 Boggo Road, Dutton Park, QLD, 4102, Australia

6 Department of Land Economy, University of Cambridge, 19 Silver Street, Cambridge, CB3 9EP, UK

4 Institute of Development Studies, Sussex University, Brighton, BN1 9RE, UK

2 Département d'Economie Maritime, IFREMER, UMR AMURE, BP 70, 29280 , Plouzanè, France

*: Corresponding author : Luc Doyen, email address : luc.doyen@orange.fr

\begin{abstract}
:
Terrestrial and marine biodiversity provides the basis for both ecosystems functioning and numerous commodities or services that underpin human well-being. From several decades, alarming trends have been reported worldwide for both biodiversity and ecosystem services. Therefore the sustainable management of biodiversity requires a double viewpoint balancing ecological conservation with the welfare of human societies. Understanding the underlying trade-offs, synergies and interactions imposes the development of interdisciplinary researches and methods. In that respect, bio-economic or ecological economic modeling is likely to play a major role. The present paper intends to elicit the key features, strengths and challenges of bio-economic approaches especially in mathematical and computational terms. It first recall the main bio-economic methods, models and decisional instruments used in these types of analyses. Then the paper shows to what extent bio-economic sustainability lies between equilibrium, viability and optimality mathematical frameworks. It ends up by identifying new major challenges among which the operationalization of ecosystem based management, the precautionary principle and the implementation of governance are especially important.
\end{abstract}

Keywords: Ecological economics ; Modeling ; Sustainability ; Biodiversity ; Public policy ; Criterion ; Equilibrium ; Optimality ; Viability 


\section{From conservation to sustainable management of biodiversity}

Global changes including climate change and changes in land-use have induced significant impacts on marine or terrestrial biodiversity at different biotic scales namely genetic, species, ecosystem. In particular, over-fishing, agricultural intensification or abandonment, species invasions raise major concerns for biodiversity with extinctions, declines, erosions and homogenization (Butchart et al., 2010; Millennium Ecosystem Assessment, 2005). These changes in species, populations, communities or ecosystems have consequences on human societies through the threats and risks that they induce on economic goods and ecosystem services. Direct use values related to food, fuel or medicine, indirect use values related to pollination, water or carbon cycles, recreational or aesthetic values, option values and adaptability can be lost or weakened, and this in a more or less irreversible way.

It is therefore necessary to sustainably manage biodiversity with a double viewpoint bringing together ecological conservation and the welfare of human societies as emphasized by the creation of the IPBES ${ }^{1}$. The underlying public policies or ecological engineering must be part of a general prospect of sustainable development, reconciling environmental economic and social requirements with a perspective of equity within and between generations. Thinking about these trade-offs and interactions imposes the development of interdisciplinary or trans-disciplinary scientific researches. Bio-economics or ecological economics can contribute to such an objective (Thebaud et al., 2013). The aim of these disciplines is basically to highlight the control of the environmental-economic systems at play by analyzing and designing decision strategies, public policies and scenarios for biodiversity together with the commodities and ecosystem services it provides.

The present paper aims at sketching the major ingredients and methods of bio-economics or ecological economics as well as at identifying recent advances and current challenges facing these disciplines especially in relation to mathematical, modeling and computational dimensions.

\section{Bio-economic methods, models and instruments}

Bio-economic approaches must rely on three key components. The first component consists in knowledge and scientific information including mechanisms, models and data. The second component refers to shared intertemporal objectives. Instruments to achieve these targets constitute the third ingredient. Figure 1 illustrates this general prospect.

This process starts with the construction of formal representations and models that make sense ecologically, economically and that are well-posed in numerical and mathematical terms. This implies that an integrated modeling approach should be implemented to handle the coupling and interactions between dynamic models of life sciences including dynamics of populations, communities, food web along with models of anthropogenic activities and pressures including agricultural or forest land-uses, fishing exploitation and regulations of agencies involved in the management or conservation of the renewable resources at play.

Bio-economic public policies are based on three types of instruments : standards, monetary, or informational instruments. Standards or norms are intended to constrain the agents through potential administrative or judicial sanctions. Examples include harvest limits on fish or wildlife,

1. International Panel for Biodiversity and Ecosystem Services : http://www.ipbes.net/. 


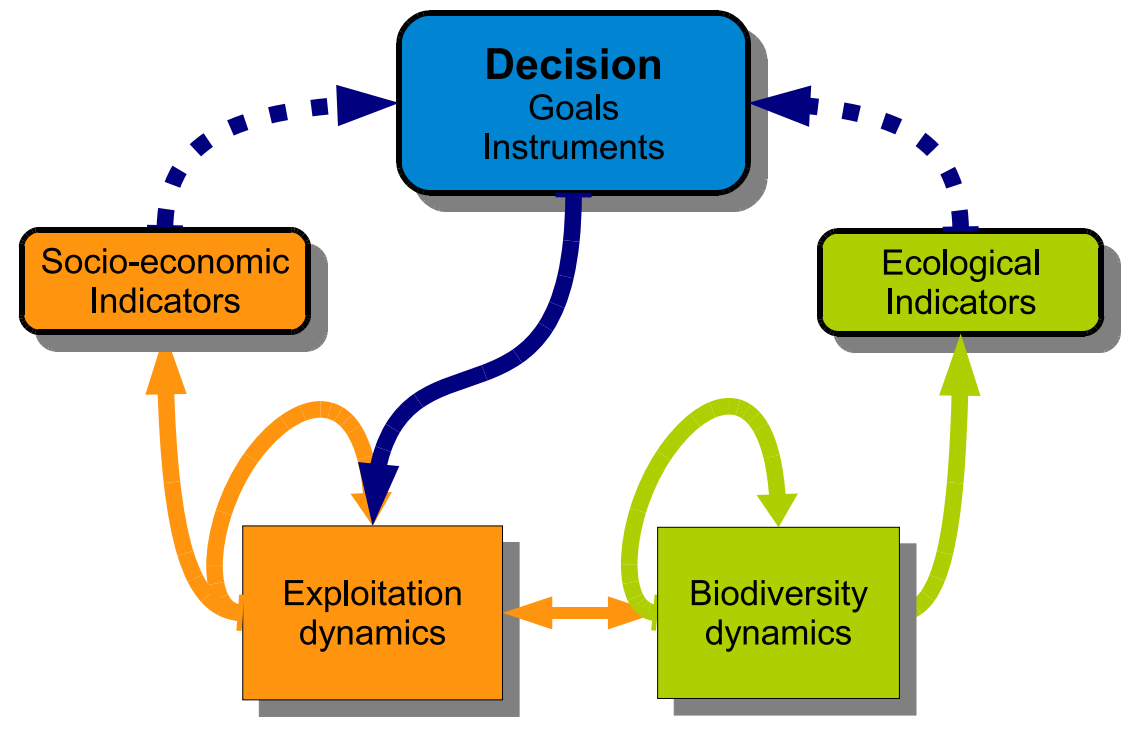

Figure 1: Conceptual model of a bio-economic approach.

protected areas. Economic and incentive-based instruments aim at encouraging more environmentally friendly behaviors through price signals. The main bio-economic financial instruments are taxes (landing, licenses, ..), subsidies, market of transferable quotas, compensation measures. Finally informational instruments are designed to favor the adoption of specific behaviors via an information signal such as eco-labeling.

Control theory of dynamical systems provides a generic formalism and transverse directions for modeling and evaluating these bio-economic issues. This was highlighted by several authors including Clark (1990) or DeLara \& Doyen (2008) for an economic perspective or Byron et al. (2002) from a conservation viewpoint. Thus the description of systems in terms of state, control, disturbance, observation allows integrated models accounting for relevant dynamics, complexities, uncertainties, information and decisions. In addition, the framework of control theory offers different decision criteria and various approaches including stabilization (typically around equilibrium), intertemporal optimization, and invariance (constraints) that are useful and complementary to address sustainability. Through stochastic and robust control, it also provides methods to manage uncertainty. This framework can also tackle issues related to strategic interactions such as cooperation and coalitions between heterogeneous agents (different fishing fleets, ...) impacting these systems by mobilizing elements of cooperative game theory or non-cooperative (Nash). Moreover, the models derived from dynamic systems' control theory promote interactions between mathematics and simulations and favors well-posed codes and numerical approximations.

A basic bio-economic model considers the state $x(t)$ of a single species whose evolution depends both on the quality of habitat as represented by its carrying capacity $k(t)$ and the effect of harvesting $h(t)=h(e(t), x(t))$ entailed by human activities $e(t)$. In discrete time, this reads

$$
x(t+1)=x(t)+f(x(t), k(t))-h(e(t), x(t)),
$$

where population dynamics $f$ accounts for density dependence through carrying capacity $k(t)$. Control of the system is usually through the effort $e(t)$ (typically fishing or hunting intensity) 
(Clark, 1990) although habitat quality $k(t)$ can also play the role of decision variable especially in terrestrial contexts and land-use management (Swanson, 1994; Mouysset et al., 2011; 2012).

\section{Bio-economic sustainability between equilibrium, viability and optimality}

Equilibrium approaches and the study of stationarities represent an important and historic step to address the sustainability in bio-economics. Thus the MSY (Maximum Sustainable Yield, see Schaefer, 1954) or MEY (Maximum Economic Yield, see Larkin et al., 2011) and bionomic equilibrium (open-access OA, see Bjørndal \& Conrad, 1987) are major reference points for the management of renewable resources as shown in Figure 2. The basic idea underlying these concepts is to set the resource stock at equilibrium by harvesting the growth (the surplus) of this stock. Typically for single species management as described in dynamics (1), we obtain the fixed point condition

$$
f(x, k)=h(e, x) .
$$

In particular, MSY maximizes the quantity of catches at equilibrium while MEY maximizes profits in equilibrium integrating economic data as selling prices of stock and costs of effort. This reads

$$
\text { MSY : } \max _{f(x, k)=h(e, x)} h(e, x) \quad \text { MEY : } \max _{f(x, k)=h(e, x)} \pi(e, x)
$$

where $\pi(e, x)$ stands for the profit derived from incomes of catch $B(h(x, e))$ and costs of effort $c(e)$ :

$$
\pi(e, x)=B(h(x, e))-c(e) .
$$

The bionomic equilibrium relies on the assumption that the rent is dissipated. It is often associated with an asymptotic situation where catch intensity varies according to profitability. These approaches are usually criticized because they are too static and have difficulty to account for uncertainty. However, despite these weaknesses, these concepts still play an important role in fisheries management or hunting for example (United Nations Convention for the Law of the Sea, 1982 ; Johannesburg Plan of Implementation, 2002)

The most common economic approaches departing from equilibrium are based on intertemporal criteria, assessment and optimality. By accounting for time, dynamics, transients or inertia, such frameworks especially informs on the recovery and rebuilding of ecological-economic systems which is crucial in practice. These approaches include cost-benefit and cost-effectiveness analyses through the sum of (generally discounted) future payoffs so-called "present value". Cost-benefit analysis refers to an intertemporal performance including discounted benefits, costs and damages. The underlying question in this type of analysis is whether the aggregate gains over time exceed the costs, damages and losses. A referenced policy is one that optimizes this criterion. Typically, focusing on profitability and harvesting controls, this reads

$$
\max _{e(0), \ldots, e(T)} \sum_{t=0}^{T} \rho^{t} \pi(e(t), x(t))
$$

where $\rho$ plays the role of discount factor and $T$ is the temporal horizon. In computational and mathematical terms, dynamic programming is an important property of such an intertemporal optimization problem because it provides a temporal decomposition of the optimal performance.

Regarding inter-generational equity, the choice of discount rate turns out to be critical as it introduces a preference for the present that may be detrimental for future generations. Interesting 


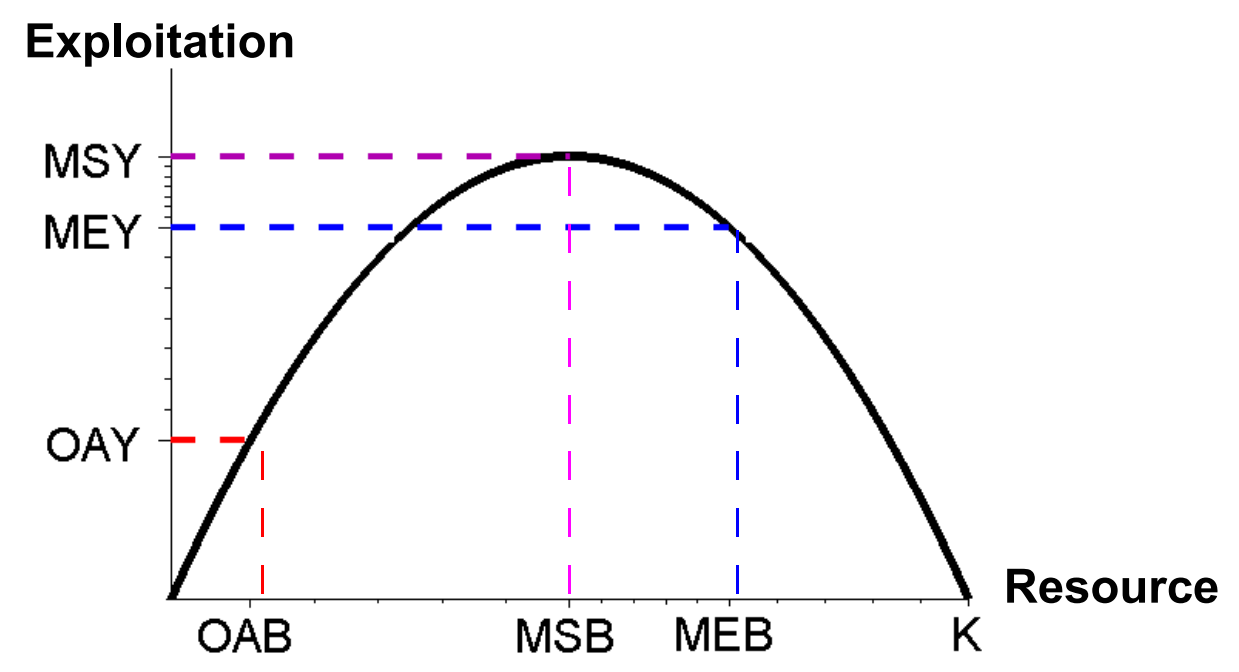

FIGURE 2: Equilibrium curve (with a logistic growth function) for the management of renewable resources with the MSY (Maximum Sustainable Yield) or MEY (Maximum Economic Yield) and bionomic equilibrium (open access) OA.

variations in this context are provided by Rawlsian or maximin criteria taking into account the most penalized generation (Heal, 1998) :

$$
\max _{e(0), \ldots, e(T)} \min _{t=0, \ldots, T} \pi(e(t), x(t)) .
$$

Another important conceptual difficulty of cost-benefit approaches for biodiversity assessment are non-market dimensions. Moreover, the prospects for resource conservation are not necessarily compatible with this approach as stressed by (Clark, 1990) since extinction can be optimal. The cost-effectiveness analysis can be used to reveal the policy of minimal cost among those achieving specific goals of conservation and exploitation usually expressed in quantities instead of prices. This approach avoids the pitfalls of monetary valuation of non-market goods. It refers generally to the optimization under constraints. Typically, in usual bio-economic contexts, we consider the problem

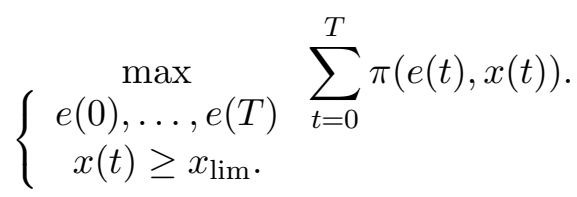

Approaches based on the idea of feasibility, viability and safety of systems may also be fruitful to address the bio-economic sustainability as pointed out in Bene et al. (2001), BaumgartnerQuass (2009) or Pereau et al. (2012). These approaches focus on the compatibility of the controlled dynamics with constraints or targets representing the good health of systems. These constraints are often ecological thresholds as inspired by the extinction of population viability analysis (PVA, Morris \& Doak, 2003). The account of socio-economics objectives (guaranteed rent, food security, ...) which is now put forward (Doyen et al. 2012, Pereau et al. 2012, Cissé et al. 2013, Gourguet et al. 2013, Hardy et al. 2013) allows for multi-criteria analyses, such as co-viability analysis shown in Figure 3. For single species management, such bio-economic 
viability refers to a mix of the following constraints

$$
\left\{\begin{array}{c}
\pi(e(t), x(t)) \geq 0, \\
h(e(t), x(t)) \geq h_{\lim }, \\
e(t) \geq e_{\lim }, \\
x(t) \geq x_{\lim } .
\end{array}\right.
$$

These approaches methodologically refer to the invariance of dynamical systems. They help to overcome the apparent antagonism between ecology, often concerned with survival and conservation issues, and economics rather focusing on the pursuit of efficiency and optimality. In the bio-economic context, strong links have been shown between the viability approach, the equilibria MSY or MEY, the Rawlsian "maximin" approach (Doyen \& Martinet 2012) and finally precautionary approaches. Strong connections with the resilience of dynamic systems were also highlighted in Martin (2004). A key mathematical tool for viability issues is provided by the so-called viability kernel (Aubin, 1990). Its computation is usually difficult since this kernel is in general not a smooth set. Of interest in computational terms is the dynamic programming structure underlying this viability kernel as pointed out in Doyen \& DeLara (2010) and detailed later in this paper for the stochastic case.
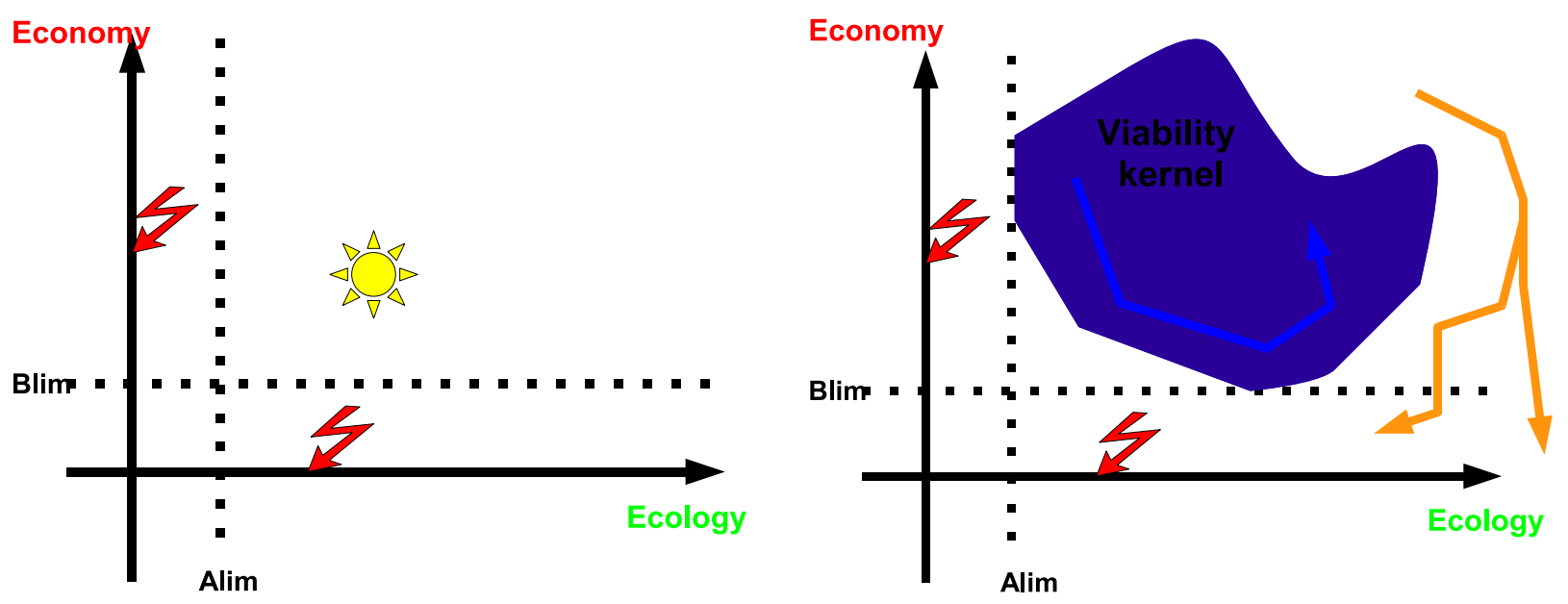

FIGURE 3: Bio-economic viability : compatibility between controlled dynamics and (ecological and economic) constraints represented by lower thresholds $A_{\text {lim }}$ et $B_{\text {lim }}$; in blue the viability kernel where co-viable strategies, scenarios and trajectories exist. Outside the kernel, the crisis can not be avoided.

\section{New bioeconomic challenges}

Despite the strong theoretical research underlying these different concepts, methods and tools and some success (Cunningham \& Bostock 2005, Gutierrez et al. 2011), the management of renewable resources, eco-systems and biodiversity remains generally unsatisfactory worldwide both in ecological and socio-economic terms. For instance, nearly two-thirds of assessed fish stocks worldwide may be in need of rebuilding (Worm et al., 2009; Larkin et al, 2011). Therefore, it is important to reinforce existing bio-economic models and/or to develop new and quantitative or qualitative methods for decision support especially in view of the IPBES creation. These tools should be able to meet new challenges. We stress here three major and stimulating challenges : 
- How to operationalize an ecosystem based management?

- How to operationalize the precautionary principle?

- Which governance for public policy?

\subsection{How to operationalize the ecosystem based management?}

Many scientists now believe that the current shortcomings of public policies and regulations for the management of biodiversity and renewable resources can be explained by an insufficient account for complexity. Typically in fisheries, they advocate an ecosystem based approach for fishery management (FAO 2003). Operationalizing such a framework is however a very difficult challenge that entails moving from mono-species based models towards multi-species, communities, trophic web management and spatially explicit models. Accounting for trophic interactions between species leads to complex models in the form of

$$
x_{i}(t+1)=x_{i}(t)+f_{i}\left(x(t), k_{i}(t)\right)-h_{i}\left(e(t), x_{i}(t)\right), \quad i=1, \ldots, n
$$

where $f_{i}$ may capture inter-specific competitions and $h_{i}$ technical interactions. The most usual form for trophic interactions is given by Lotka-Volterra form as in Cissé et al. (2013), Hardy et al. (2013). Regarding computational issues, graph and network theory should play an important role for the study of food webs and ecosystem based management.

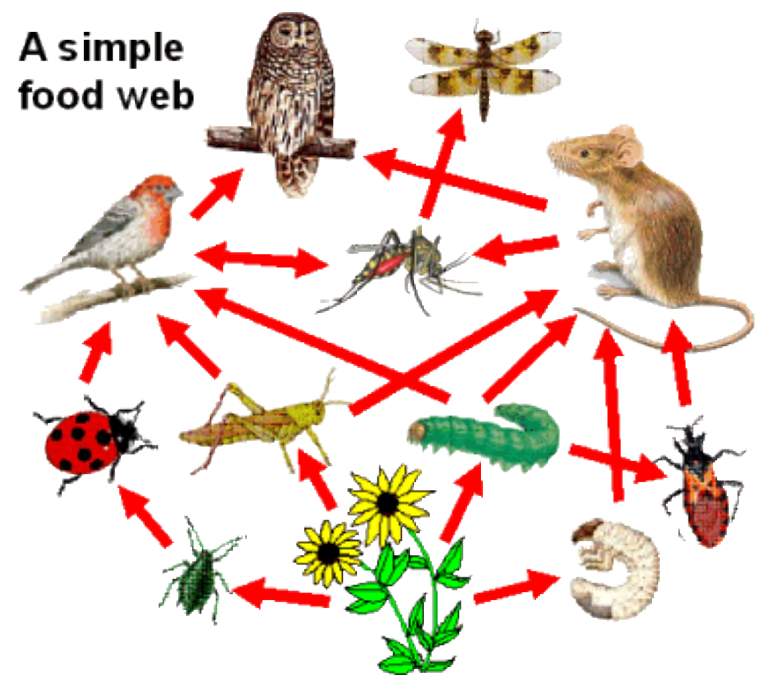

Figure 4: A trophic web.

Similarly in agriculture, some current difficulties are due to ignorance of some systemic effects (environmental, social, nutritional, ..) and interdependencies within the living world as well as between it and physicochemical processes. Many scientists are now pleading for a multifunctional agriculture. In this regard, the management of biodiversity through habitat quality, land-uses affecting carrying capacities $k_{i}(t)$ is relevant as in Mouysset et al. $(2012,2011)$ or Swanson (1993). The role played by ecosystem services such as pollination, water cycle, carbon cycle are at the core of these frameworks. A line of high complexity for farming and forestry systems is the spatiality and territoriality.

These ecosystem approaches emphasize the need for biodiversity indicators $B\left(x_{1}(t), \ldots, x_{n}(t)\right)$. Nevertheless, the choice of relevant diversity metrics remain the subject of numerous debates. 


\subsection{How to operationalize the precautionary principle?}

Uncertainties in the mechanisms and the state variables are often challenging in bio-economic contexts. They can justify in many cases the absence or delay of decision ("wait and see") because of lack of knowledge and scientific certainty. It is the essence of the precautionary principle to attempt to solve these situations of indecision. In these cases, decision under uncertainty and risk management must be mobilized. Focusing on previous multi-species issues in discrete time, we need to consider the controlled dynamics

$$
x_{i}(t+1)=x_{i}(t)+f_{i}\left(x(t), k_{i}(t), \omega(t)\right)-h_{i}(e(t), x(t), \omega(t)),
$$

where $\omega(t)$ represents the uncertain scenarios affecting the dynamics. A difficulty for decision under uncertainty in environmental context is that the decision makers face different types of uncertainty. Indeed uncertainties based on data and measures (population dynamics, ..) are probabilistic or Bayesian in nature, while other uncertainties sometimes called "Knightiennes" are linked to controversies, beliefs, scenarios (economic growth, price dynamics, climate scenario) without strong statistical foundation. We can distinguish stochastic uncertainty and ambiguity. A second difficulty lies in the irreversibility of dangerous situations, crises and damages. In other words, the loss of biodiversity are often problems of extinction or symmetrically survival and viability. In multi-species context where uncertainties have a probabilistic nature, the bioeconomic viability consists in the fulfillment of constraints with a maximal probability namely

$$
\left.V\left(t_{0}, x_{0}\right)=\max _{\text {strategy } e(.)} \mathbb{P}(\pi(e(t), x(t))) \geq 0, \ldots, B(x(t)) \geq B_{\lim } \text { for } t=t_{0}, \ldots, T\right) .
$$

where $x(t)=\left(x_{1}(t), \ldots, x_{n}(t)\right)$ is the vector of species state. At this stage, it is worth pointing out that relevant type of decision strategies are given by feedback controls in the form of $e(t, x)$. This derives from the dynamic programming structure underlying the probabilistic viability problem stressed in Doyen \& DeLara (2010) :

$$
V(t, x)=\max _{\text {e s.t. } \pi(e, x) \geq 0} \mathbb{E}_{\omega}\left[\mathbf{1}_{\left\{B(x) \geq B_{\lim }\right\}}(x) \cdot V(t+1, x+f(x, \omega)-h(x, e, \omega))\right]
$$

where $\mathbf{1}_{\left\{B(x) \geq B_{\lim \}}\right.}$ means the characteristic (boolean) function associated with the constraint while $f$ or $h$ represents the vector forms of $f_{i}$ or $h_{i}$ functions respectively. Another difficulty is related to the dynamic structure of uncertainty and scientific knowledge. Indeed scientific knowledge enhances throughout time and some uncertainties can be reduced. The concept of information value and so-called flexibility (or irreversibility) effect can give insights in this context. It is also relevant to analyze the extent to which the diversity and heterogeneity (versus specialization) promote the sustainability of bio-economic systems by taking advantage of uncertainties and exogenous fluctuations. The test of such a "insurance hypothesis"' (Loreau, 2001) at bioeconomic scales questions the positive role play by diversity both at the biotic level and in human strategies (Béné \& Doyen, 2008 ; Mouysset al. 2013).

\subsection{Which governance for bio-economic policies?}

The heterogeneity of agents involved in environmental and ecological processes also contributes to the complexity in the design of public decision and management. Agents including fishers, farmers, hunters, conservation agency, regulation agency, tourists or NGO can differ in 
their preferences, their strategies, their level of information and their inputs in the dynamics of systems. Expanding the previous models, this means that

$$
h_{i}(x(t), e(t))=\sum_{\text {agents } j} h_{i j}\left(x(t), e_{j}(t)\right)
$$

where $e_{j}(t)$ stands for the decision (effort) of each agent. Moreover some agents have inertial or myopic strategies, while others may set their decisions on "rational" ground. Furthermore, agents do not take into account all the external consequences of their actions. Derived in bioeconomic terms, a catastrophic and irreversible outcome of such a process is the resource collapse as stressed by the tragedy of open access (Hardin, 1968). Moreover, the goals of different agents or groups are often contradictory and the definition of public policies may result in trade-offs. Arbitration is key. In line with this, it is worth noting that the most recent progresses in science relating to the environment and ecology have not yet led to a real convergence of viewpoints on the best policies to select and implement. Social sciences are thus required to build consensus, coordinations and participatory methods. In this perspective, the use of evolutionary games, multi-agent and game theory in both their non-cooperative and cooperative branchs should be fruitful.

Regarding bio-economic viability issues and game theory, while the cooperative case could be easily expanded using equation (2), the non cooperative situation would correspond to solve in the Nash sense the following set of optimality problems for any agent $j$ :

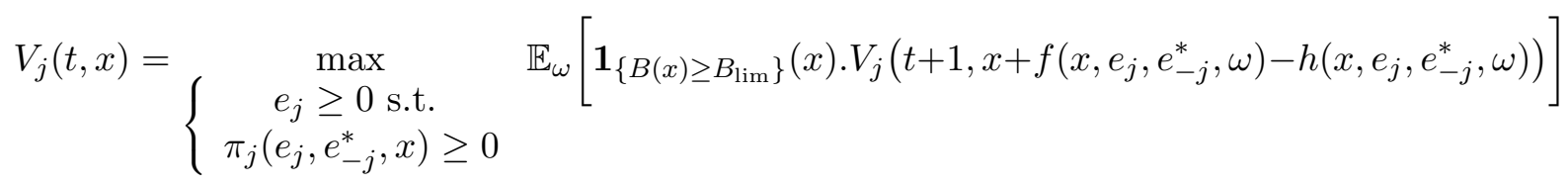

where $e_{-j}^{*}=e_{-j}^{*}(t, x)$ means a viable feedback decision of agents different from $j$. The set of viable decisions and states underlying this non cooperative context, whenever it would exist and differ from the empty set, could be informative in a context of negotiations as a relevant space of convergence for acceptable and sustainable policies, reference points and confident rates. Such a framework also paves the road for the analysis of coalition sustainability and stability as suggested in Doyen \& Pereau (2012).

\section{Conclusion}

The present paper advocates the use of bio-economic modelling to sustain biodiversity with a double viewpoint balancing ecological conservation with the welfare of human societies. It attempts to elicit the major features, strengths and challenges of bio-economic approaches. The examples derived from fisheries, forestry or agriculture illustrate this general bio-economic analysis. In terms of strengths of the prospect, several points have been put forward. The first advantage of such bio or ecological economic models is to contribute to clear formalizations of the dynamic interactions between ecological and socio-economic systems at play. In particular, this promotes the identification of the potential controls, decisions or policies that can be applied to these integrated systems to modify their trajectories. The second advantage of such models is to stress the multidimensional objectives underlying sustainability and the underlying trade-offs between these possibly conflicting targets through criteria or constraints. 
As regard new challenging perspectives for bio-economics, we have paid attention to three. The first challenge is the operationalization of ecosystem based approaches accounting in particular for the numerous complexities of the systems considered. This also means to clarify the characterization and the use of biodiversity indicators and ecosystem services. The second main challenge relates to the precautionary principle and the necessary account of uncertainties in the decision process and risk management. The third is associated with governance issues for public policies and the development of methods integrating strategic interactions between heterogeneous and possibly conflicting agents.

\section{Acknowledgment}

This work has been carried out with the financial support of the ANR (French National Research Agency) through the ADHOC and FARMBIRD programs. The support from IHP (Institut Henri Poincaré) in Paris during the trimester "mathematics of bio-economics" in the framework of Mathematics of Planet Earth 2013 initiative was important.

\section{References}

[1] Aubin, J-P. 1990. A survey of viability theory. SIAM Journal on Control and Optimization, 28(4), 749-788.

[2] Béné C., Doyen L. \& Gabay D. 2001. A Viability Analysis for a Bio-economic Model. Journal of Ecological Economics, 36, pp 385-396.

[3] Béné C. \& Doyen L. 2008. Valuing biodiversity and the contribution of species richness to ecosystem sustainability. Ecological Economics, 68, 1-2, 14-23.

[4] Bjørndal T. and Conrad M. J. 1987. The Canadian Journal of Economics, 20, 1, pp. $74-85$

[5] Butchart et al. 2010. Global Biodiversity : Indicators of Recent Declines, Science, Vol. 328 no. 5982 pp. $1164-1168$

[6] Byron K.W., Nichols J. D., and Conroy M. J. 2002. Analysis and Management of Animal Populations. Academic Press.

[7] Cissé A., Gourguet S., Blanchard F., Doyen L., Pereau J.-C. 2013. A bio-economic model for the viable management of the coastal fishery in French Guyana, Environmental and Development Economics, 1-25.

[8] Clark C. W. 1990. Mathematical Bioeconomics. second edn. New York : Wiley.

[9] Cunningham S. \& Bostock T. 2005. Successful fisheries management : Issues, case studies, perspectives, Eburon Publishers, Delft.

[10] DeLara M. \& Doyen L. 2008. Sustainable Management of Natural Resources : Mathematical Models and Methods, Springer.

[11] Doyen L., DeLara M. 2010. Stochastic viability and dynamic programming, Systems and Control Letters. 59, 10, 629-634. 
[12] Doyen L., Pereau J.-C. 2012. Sustainable coalitions in the commons, Math. Social Sciences. 63. 57-64.

[13] Doyen L., Thébaud O., Martinet V., Gourguet S., Béné C., Bertignac M., Fifas S., Blanchard F. 2012. Stochastic viability to ecosystem-based management of multi-species fisheries, Ecological Economics, 75, 3242

[14] FAO. 2003. The ecosystem approach to fisheries. FAO Technical Guidelines for Responsible Fisheries 4, Suppl. 2. FAO. 112 pp.

[15] Gutiérrez N.L., Hilborn R. \& Defeo O. 2011. Leadership, social capital and incentives promote successful fisheries, Nature, 470, 386-389

[16] Hardy P.-Y., Doyen L., Béné C., Schwartz A.M. 2001. Food security-environment conservation nexus : a case study of Solomon Islands' small-scale fisheries. Environmental Development. http://www. sciencedirect.com/science/article/pii/S2211464513000584

[17] Heal G. 1998. Valuing the Future, Economic Theory and Sustainability. Columbia University Press, New York.

[18] Larkin S. L., Alvarez S., Sylvia G., Harte M. 2011. Practical Considerations in Using Bioeconomic Modelling for Rebuilding Fisheries, OECD Food, Agriculture and Fisheries Working Papers.

[19] Loreau M. et al. 2001. Biodiversity and Ecosystem Functioning : Current Knowledge and Future Challenges, Science, Vol. 294 no. 5543 pp. 804-808

[20] Martin S. 2004. The cost of restoration as a way of defining resilience : a viability approach applied to a model of lake eutrophication. Ecology and Society 9(2) : 8 .

[21] Millenium Ecosystem Assessment. 2005. Ecosystems and human well-being, Island Press, Washington, DC.

[22] Morris W.F. and Doak D.F. 2003. Quantitative Conservation Biology : Theory and Practice of Population Viability Analysis. Sinauer Associates.

[23] Mouysset L., Doyen L., Jiguet F. 2013. Economic risk aversion to promote biodiversity. Ecological Applications. 23 : 96-109.

[24] Mouysset L., Doyen L., Jiguet F. 2012. Different policy scenarios to promote various facets of biodiversity. Ecological Indicators. 14, 209-221.

[25] Mouysset L., Doyen L., Jiguet F. Allaire G., Leger F. 2011. Bio economic modeling for a sustainable management of biodiversity and agriculture, Ecological Economics, 70, 4, 617-626

[26] Pereau J.-C., Doyen L., Little R., Thebaud O. 2012. The triple bottom line : Meeting ecological, economic and social goals with Individual Transferable Quotas, Journal of Environmental Economics and Management. 63 : 419434. http://dx.doi.org/10.1016/j.jeem.2012.01.001 
[27] Schaefer M.B. 1954. Some aspects of the dynamics of population important to the managment of the commercial marine fisheries. Bull. Int. Amer. trop. tuna comm., 1 (2). pp.2656.

[28] Swanson T. M. 1994. The Economics of Extinction Revisited and Revised : A Generalized Framework for the Analysis of the Problems of Endangered Species and Biodiversity Losses, Oxford Economic Papers New Series, Vol. 46, Special Issue on Environmental Economics, pp. 800-821

[29] Thébaud O., Smith T., Doyen L., Planque B., Lample M., Mahevas S., Quaas, M., Mullon C., Vermard Y., Innes J. 2013. Building ecological-economic models and scenarios of marine resource systems : workshop report. Marine Policy http://dx.doi.org/10.1016/j.marpol.2013.05.010 